of the objects in view. As, in the Italian sky the golden orb sank with the dark planet spot on its disk, under brightly tinted clouds, shaded off in streaks of tender grey into the azure above, with the blue rose-tipped mountains of the Esterets beneath,- the scene was one as fascinating in beauty as it was interesting in science. All these tints appeared distinctly, albeit aintly, in the telescopic image on the card.

One point was remarkable, - that whilst the shades of the mountains were all blute, the dark round spot of the planet on the sun was almost black. It was the darkest object in the field of view. Partly, but I hardly think entirely, this may be explained by its being higher, and less subjected to the decomposing power of the lower atmospheric layers. I have endeavoured to represent in water-colours this view of the transit of Venus. The result, of course, cannot be reproduced in print, but any of your readers who may be visitors at Cannes will be welcome to see it, as an original kind of reminiscence of a very rare event.

Cannes, December 2 I

C. J. B. Williams

\section{The Comet during the Last Month}

SiNCE my last communication (see NATURE, vol. xxvii. p. I IO) the weather and the presence of moonshine has been unfavourable for views of the comet; but I have seen it, more or less distinctly, on seven nights, from November 22 to December 2 I. I will not take up your space with details, but mention, as the general result of these observations, that the comet has become smaller in dimensions, and much fainter in its light. With moonlight, no trace of a tail is visible; and the nucleus can only be discerned by telescope as a nebulous star of third magnitude. In absence of moonlight, as on December 6,8 , and I 2 , between 2 and $3.30 \mathrm{a} . \mathrm{m}$., the tail was visible to a length of about $\mathrm{IO}^{\circ}$, with a breadth expanding from the head, with no distinguishable outline. My last view of it was on the 2oth, at 3 a.m., when, with a brilliant starlight after moonset, the comet was in the south-south-east, about $20^{\circ}$ above the horizon, with a tail about $8^{\circ}$ long, and a nucleus, a nebulous star of third or second magnitude. Its position was about as far to the eastnorth-east of Procyon as that star is east-south-east of Sirius. It seems likely to be visible in clear moonless nights for two or three weeks longer.

Cannes, December 2 I

C. J. B. Williams

\section{The Heights of Auroras}

THE observations described in your last number as having been made long since in Siberia, of lunar halos projected on auroras, have not, I believe, been confirmed by other observers; but if correct, possibly this phenomenon may be a peculiarity of aurol as in tSiberia, or in the Arctic regions. There seems re 1 son to think (see Capron's "Aurorre," pp. 37-40) that auroras may be lower when near the magnetic pole than further south. If this is the case, it is so far favourable to the theory (propounded, I think, by a German writer) described in NATURE (Vol. xxv. p. 320), that the auroral zone is a plane, and not part of a sphere concentric with the earth's surface. The majority of the observations in lower latitudes cited in Capron's "Auroræ," place the phenomenon at a height of 100 miles or upwards.

The height of the spindle-shaped object seen in the aurora of November 17 is thus no argument against its auroral character, which I see no reason to doubt. It is true that in my experience (which, in this northern part of the country is probably much greater than that of your correspondents), I have never seen anything resembling it, judging from the descriptions of it ; but $I$ do not think this is a reason for supposing such an auroral phenomenon could not take place. 'The fact that it moved along a parallel of magnetic latitude is a very strong argument for its auroral character. Besides, its spectrum is stated to have exhibited the characteristic auroral line. I hope some one will collect all possible observations of this beam, especially from the continent, and undertake a careful investigation into its path and height.

Sunderland, December 23

\section{The Aurora and its Spectrum}

IN reference to Mr. Ralph Abercrombie's letter (NATURE, vol. xxvii. p. I73), I may mention that his remarks quite accord with an opinion expressed to me by my friend, H. R. Procter, that the "aurora is generally formed in some imperfect mist or vapour." I am intending some experiments on discharges in vacuo under such conditions and reduced temperatures, also on phosphorescence, in connection with which M. Lecoq de Boisbaudran has shown in. his "Spectres lumineux," that we get a line in the red, brightening as the temperature is reduced. I do not read the result of my Swan lamp experiment, as $\mathrm{Mr}$. Munro (same number and page) does. The lamp, when perfect, gave quite a bright white glow, with a strong carbon spectrum. I should therefore attribute the absence of the nitrogen spectrum at this time not so much to a high spectrum as to the probability that the lamp had been, as far as possible, exhausted of air, and filled with some form of carbon gas. I am not aware of any air-vacuum point at which the nitrogen bands or lines disappear, except for want of light in the discharge. With regard to the letter of W. M. F. P. on the "Meteor of November 17th," I only assumed the correctness of the figures and heights quoted in mine for the purpose of showing the complex nature of the auroral questions. I am not the less perfectly satisfied that the "beam" was a true aurora, and not a meteor, my spectroscopic observation of it putting this beyond a doubt.

Guildown, December 23

J. RAND CAPRON

\section{The Weather}

IT is curious how the recent auroræ have been followed not only by a cold wave, but by a subsequent warm one, and these respectively of such extremes, that $2 I^{\circ}$ at $9 \mathrm{a} . \mathrm{m}$, on the $I \mathrm{Ith}$ is this day re. placed by $48^{\circ}$ or $27^{\circ}$ of difference. Equally strange bave been the effects on animal and vegetable life. During the cold, an almost Arctic season in its ice-bound stillness prevailed, and a flock of wild geese crossing in front of the house (the forerunners, in public opinion, of a hard winter) represented external creature life. Now all is changed almost to spring. Roses, though somewhat nipped by the frost, seem ready to blow; flies and gnats are unthaving, and last night, in going up to the observatory, I noticed the phosphorescent glimmer of a luminous centipede under one of the shrubs, a sight I do not remember ever to have met with in winter before.

J. RAND CAPRON

Guildown, December 19

\section{A Common Defect of Lenses}

A CHANCE observation a few weeks since led me to the discovery of a serious defect in the object-glass of the collimator of a spectroscope by Grubb, of Dublin, which I have been using for some time. As further investigation has shown me that the defect is very common, while at the same time it is a source of considerable error in all experiments on the plane of polarisa. tion of polarised light, it seems worth while to call the attention of readers of Nature to it. The object-glass in question has been imperfectly annealed. As a consequence, a plane polarised incident beam is elliptically polarised on emergence from it.

If it be looked at between crossed Nicols in a pencil of parallel rays, the field of view becomes bright, and is crossed by two brushes hyperbolic in form, which for two position; of the lens became two straight lines. If again plane polarised light be allowed to pass through the lens while it is turned round its own axis, there are four positions of the lens for which the central portion of the emergent beam is plane polarised, and can be quenched by an analysing Nicol ; for all other positions of the lens, the emergent beam is elliptically polarised, and the light cannot be quenched, but reduced to a minimum. Moreover, as the lens is turned, the position of the axes of the ellipse varies by nearly half a degree. I have since examined a large number of lenses, without finding one quite free from the defect. One well-known London optician declines to attempt to supply me with a two-inch object-glass which shall not show it, while another states he has never known any lens absolutely free from it.

The important bearing of the point on all investigations into the polarisation of light is obvious. The consequences it produces in modifying the results of some recently-published experiments of mine (Phil. Trans., Part ii., 1882) formed the subject of a paper read at the last meeting of the Royal Society.

Trinity College, Cambridge, December 20 R. T. GlazebrooK

\section{New Deep-Sea Fish from the Mediterranean}

My letter in NAtuRE, vol. xxy. p. 535 , called forth two important notes from such competent ichthyologists as Mr. J. Y. 